\title{
The time course of phonological, semantic, and orthographic coding in reading: Evidence from the fast-priming technique
}

\author{
HYE-WON LEE, KEITH RAYNER, and ALEXANDER POLLATSEK \\ University of Massachusetts, Amherst, Massachusetts
}

\begin{abstract}
The present experiment employed the fast-priming paradigm in reading (Sereno \& Rayner, 1992), in which sentences are silently read while eye-movement-contingent changes are made on a specified target region. In this paradigm, when readers fixate on a specified target word region, a prime word is encountered for a brief duration at the beginning of the fixation and then it is replaced by a target word. Three types of primes were employed: homophones, semantically related, and orthographically sim$i l a r$, and five prime durations were employed: $29,32,35,38$, and $41 \mathrm{msec}$. The primary finding was that significant homophone priming was obtained at prime durations ranging from 29 to 35 msec, whereas significant semantic priming occurred only at the $32-\mathrm{msec}$ prime duration. In contrast, significant orthographic priming occurred at all prime durations. These findings indicate that phonological codes are activated during an eye fixation at least as rapidly as semantic codes. An explanation for the pattern of events is suggested using the framework of an activation-verification model.
\end{abstract}

When readers are given the sentence "She has blond hare," they take longer to decide that it is unacceptable than "She has blond harm" (Treiman, Freyd, \& Baron, 1983). This finding indicates that phonology plays some role during reading because the longer decision means that readers extracted phonological codes from the word, hare, and these phonological codes in turn activated the lexical entry, hair, resulting in the longer decision time in the sentenceverification task. The usefulness of phonology during reading seems clear in terms of a strategy since it aids sentence comprehension by retaining phonological codes of words in working memory (Baddeley, Eldridge, \& Lewis, 1981; Kleiman, 1975: Slowiaczek \& Clifton, 1980; Taft, 1991).

A key question is whether the activation of phonology is a rapid, automatic process that influences early stages of word identification during reading. Many studies have shown that phonological codes are rapidly activated during (1) reading (e.g., Lee, Binder, Kim, Pollatsek, \& Rayner, 1999; Pollatsek, Lesch, Morris, \& Rayner, 1992; Rayner, Pollatsek, \& Binder, 1998; Rayner, Sereno, Lesch, \& Pollatsek, 1995), (2) single-word identification (e.g., Perfetti \& Bell, 1991; Perfetti, Bell, \& Delaney, 1988), and (3) semantic judgments (e.g., Lesch \& Pollatsek, 1998; Van Orden, 1987; Van Orden, Johnston, \& Hale,

This research was supported by Grant HD 26765 from the National Institutes of Health. K.R. was also supported by a Research Scientist Award from the National Institute of Mental Health (MH 01255). We thank Ludovic Ferrand, Ken Forster, and Chuck Perfetti for their helpful comments on an earlier version of the article. Requests for reprints should be addressed to H.-W. Lee or K. Rayner, Department of Psychology, University of Massachusetts, Amherst, MA 01003 (e-mail rayner(a)psych.umass.edu).
1988). However, there is still not general agreement upon how much weight should be put on the role of phonology (Daneman, Reingold, \& Davidson, 1995). One view, the classical dual-route model, assumes that phonology plays a role only if direct lexical access (i.e., directly from orthography) is slow. On this view, lexical access is almost exclusively through the direct visual route and phonology plays a role chiefly for low-frequency words. The key evidence for this view is that the regularity effect (i.e., longer naming or lexical decision times for words with irregular grapheme-to-phoneme correspondences than for words with regular correspondences) is largely limited to lowfrequency words (Bauer \& Stanovich, 1980; Seidenberg, Waters, Barnes, \& Tanenhaus, 1984; but see Jared, 1997). An opposing view, which is often couched in terms of a phonological mediation model (Lukatela \& Turvey, 1994; Perfetti \& Bell, 1991; Perfetti et al., 1988; Van Orden, 1987; Van Orden et al., 1988), assumes that phonology plays a dominant role in written word identification because language is fundamentally a spoken medium. Note that both views accept the premise that phonological codes play a role in the identification of printed words; the issue is largely whether they play a dominant or minor role.

\section{Lexical Versus Nonlexical \\ Computation of Phonological Codes}

What is the nature of early phonological coding in reading? One way to frame this issue is to think in terms of separate mechanisms of phonology: addressed (or lexically based) phonology and assembled (or rule-based, nonlexical) phonology. If only lexical phonology is involved in reading, then the only way that the word hare can activate the meaning of hair would be to first activate the 
"hare" entry in the orthographic lexicon, which would activate the sound of the word, which would, in turn, activate the meaning of hair. There is evidence, however, from studies using nonwords (Perfetti \& Bell, 1991; Perfetti et al., 1988; Van Orden et al., 1988) indicating that assembled phonology is extracted earlier in reading than would be predicted by such a model. For example, Van Orden et al. showed, in a semantic categorization task, that subjects are more likely to categorize jeap as a member of the category "vehicle" than jelp. Phonological codes for nonwords like jeap cannot be accessed through the lexicon, because they have no lexical entry. In addition, Lesch and Pollatsek (1998) showed that subjects were slow to decide that pillow and bead were unrelated because bead could be decoded as / bed/ through assembled phonology. This indicates that the involvement of assembled phonology is not restricted to processing nonwords.

There is also evidence, however, suggesting that early activation of phonology is largely addressed. Earlier, we mentioned that irregularity in orthography produces little interference in processing high-frequency words, and thus, according to a dual-route account, the competing assembled phonological representation is too slow to affect processing. A recent study by Lee et al. (1999) led to a similar conclusion using a different paradigm (the fastpriming paradigm that was used in the present experiment). The procedure will be described in more detail below, but the essential idea is that subjects read sentences and a prime is briefly presented during a single fixation and then replaced by a target word that makes sense in the context. Lee et al. found that fixation times on the target word were shorter when the prime was a homophone than when it was an orthographic control word, but only when the homophone prime was a high-frequency word and not when it was a low-frequency word or a pseudoword. This suggests again that lexicality affects the early stages of phonological coding.

\section{Presemantic Versus \\ Postsemantic Access of Phonology}

More relevant to the present experiment is the issue of whether phonology is accessed before or after the access of meaning. This is separate from the issue of assembled versus addressed phonology. That is, even if phonology is completely addressed, it may still activate meaning prior to the activation of meaning by an orthographic code. To make this point clear, again consider the sentence "She has blond hare." If one assumes that phonology is assembled directly from the orthography, then it would essentially follow that access to the lexical entries hare and hair and their meanings is mediated by phonology (presemantic access). On the other hand, if one assumes that phonology is largely addressed, there are two possibilities for how meaning is accessed. One is that the meaning of hare in the lexicon is accessed first from its orthographic information, which accesses the phonological representation of /hair/, which, in turn, activates the meaning of the other lexical entry, hair (postsemantic access). The other is that phonological information stored in the lexicon could be accessed first from the orthographic information, which in turn is the primary route for activating the meaning of the two lexical entries, hare and hair (presemantic access). Thus, whether the activated phonology is lexical or nonlexical is not the point here. The critical question is whether access to phonology precedes access to meaning. We will defer further discussion of mechanisms until later.

\section{Rationale for the Present Study}

In the present study, we examined the time course of phonological, semantic, and orthographic priming in a reading situation. Of primary interest was the relation between phonology and meaning access. We wanted to compare the speed of extraction of phonology and of meaning early in an eye fixation during reading. For this purpose, the fast-priming technique developed by Sereno and Rayner (1992) was used. An illustration of the procedure is presented in Figure 1. A string of random letters ( frtkw) initially occupies a target location as a reader reads a sentence (a). The purpose of the initial random-letter string is to eliminate meaningful parafoveal processing of the target region until the word is fixated. When the eyes cross an invisible boundary, the random letters are replaced by a prime (e.g., beach), which remains for a specified duration after the onset of an eye fixation (b). The prime is then replaced by a target word (beech), which remains in place while the reader finishes reading the sentence (c). The fixation time on the target word is then examined as a function of the relation between the prime and target. When the prime duration is brief, readers are typically not aware of the identity of the prime word even though it has an effect on processing. They are also not aware of the change from the random letter string to the prime, though they are aware that something changed when the prime changes to the target word. Our fast-priming technique is thus similar in general outline to other fast-priming techniques (Forster \& Davis, 1984). The major advantage of the technique is that it can be used to study word identification in the silent reading of text with minimal disruption of normal reading. A second advantage is that the fixation times obtained are appreciably shorter than manual

\section{a. The bird prefer|s frtkw trees for nesting. $-->*$ \\ b. The bird prefer|s beach trees for nesting.

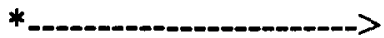 \\ c. The bird prefer|s beech trees for nesting.}

Figure 1. An illustration of the fast-priming technique. (The vertical lines indicate an invisible boundary, an arrow indicates the movement of eyes, and a star indicates a fixation.) 
or vocal latencies, so that one is capturing a more immediate response to the manipulation.

Several prior studies have employed this technique (Lee et al., 1999; Rayner et al., 1995; Sereno, 1995; Sereno \& Rayner, 1992). Two investigated early involvement of phonological coding by comparing the effects on fixation times of homophone primes with the effects of orthographic control primes. Rayner et al. (1995) found a phonological priming effect with a $36-\mathrm{msec}$ prime duration, and Lee et al. found a phonological priming effect with 32- and 35-msec prime durations. ${ }^{1}$ Two others found semantic priming - shorter fixation times when the prime was a semantic associate of the target word than when it was unrelated-at prime durations of $30 \mathrm{msec}$ (Sereno \& Rayner, 1992) and $35 \mathrm{msec}$ (Sereno, 1995). ${ }^{2}$ There was also evidence for the early extraction of orthographic codes since fixation times were shorter when the target word was preceded by an orthographically similar prime than when it was preceded by an orthographically dissimilar prime. Orthographic priming was obtained at all prime durations employed in the above experiments (24-42 msec). This was in contrast to the pattern for both phonological and semantic priming. In both semantic priming studies, no priming was found at either shorter or longer prime durations, and in the Rayner et al. (1995) study, no phonological priming was found at shorter durations (the 36 msec prime duration was the longest), and in the Lee et al. study, no phonological priming was found at the other, longer durations employed (the 32- and 35-msec durations were the shortest).

The above pattern of results is intriguing but far from definitive. First, it is not clear what window of times phonological and semantic priming can occur in. Many of the prior studies employed only a few prime durations, which were relatively widely spaced (usually by about $6 \mathrm{msec}$ ), to ensure that priming occurred in at least one of the intervals employed. Most importantly, however, is the temporal relationship between phonological and semantic priming. The prior studies indicated that they occurred in more or less the same temporal window. However, the semantic priming studies and phonological priming studies were separate experiments done with different subjects and not exactly the same equipment (see note 2). In the present experiment, we employed a larger number of prime durations, all within a relatively narrow temporal window ( $29-41 \mathrm{msec})$ to uncover the time course of phonological and semantic fast priming. In addition, both effects were assessed in the same session, so that the relative time course of the two effects would be captured.

\section{METHOD}

\footnotetext{
Subjects

Thirty members of the University of Massachusetts community were paid to participate in the experiment. They all had normal vision and were naive with respect to the purpose of the experiment.

Apparatus

The target sentences were presented in lowercase letters (except when capitals were appropriate) on a ViewSonic $17 \mathrm{G}$ monitor (with
}

standard VGA characters) that was controlled by a super-VGA graphics board with a Tseng chip interfaced with a 486 computer. All sentences were displayed on a single line with a maximum length of 60 characters. Subjects were seated $61 \mathrm{~cm}$ from the monitor and three characters equaled $\mathrm{I}^{\circ}$ of visual angle. The brightness of the monitor was adjusted to a comfortable level for each subject and held constant throughout the experiment. The letters were presented in light cyan (on a black background) by mixing the green and blue input signals on the display monitor with a $\mathrm{P}-22$ phosphor, which allowed blanking of a display to produce a drop to $10 \%$ of maximum brightness in $.06 \mathrm{msec}$. Subjects' eye movements were monitored with a Fourward Technologies Dual Purkinje Eyetracker (Generation V), which was interfaced with the computer. The eyetracker has a resolution of less than $10 \mathrm{~min}$ of arc, and its signal was sampled every millisecond by the computer. Viewing was binocular, with eye movements recorded from the right eye.

\section{Materials and Design}

A target word was embedded in each of 150 experimental sentences, with 50 sentences assigned to each priming condition: phonological, semantic, and orthographic. Because we could not obtain enough quadruples matched for length and frequency to satisfy our investigation, we used different target words across the three priming conditions. For each target word, there were two prime types (equal in word length to the target). For a target word in the phonological priming condition (beech), a prime was either a homophone of the target (beach) or an orthographic control (bench) in which the prime was as orthographically similar to the target as the homophone. ${ }^{3}$ For a target word in the semantic priming condition (hate), a prime was either semantically related or unrelated (club) to the target (love). For a target word in the orthographic priming condition (horse), a prime was either orthographically similar to the target (house) or orthographically dissimilar (thing). Hobbs (1986) was consulted for homophone primes, and Postman and Keppel (1970) was consulted for semantic primes.

The length of the target words ranged from three to seven letters. The mean word frequency (according to Francis \& Kučera, 1982) of the targets was 53, and the mean frequency of the primes was 154. The various pairs of conditions were each matched with respect to frequency: (1) for the phonological priming condition, targets -40 , homophone primes-157, orthographic control primes-157; (2) for the semantic priming condition, targets -65 , semantically related primes - 151 , semantically unrelated primes-151; and (3) for the orthographic priming condition, targets--55, orthographically similar primes - 152 , orthographically dissimilar primes153. We used relatively high-frequency primes because the results of Lee et al. (1999) indicated that there was only a clear priming effect for homophone primes with high frequency. All experimental sentences, including targets and primes, are presented in the Appendix.

Five prime durations $(29,32,35,38,41 \mathrm{msec})$ were used in each priming condition. These durations were chosen for two reasons: First, we wanted to investigate the time course of priming within a relatively narrow temporal window, and second, extending durations up to longer ones (such as $50-60 \mathrm{msec}$ ) could interfere with a subject's reading process by making him/her consciously aware of the prime. Although each target word in each priming condition (phonological, semantic, and orthographic) could appear in any of 10 conditions (two prime types $\times$ five prime durations), a given subject saw each target word in only 1 of the 10 conditions, and the assignment of the stimuli to a condition was counterbalanced across subjects. The sentences were presented in a different random order for each subject.

\section{Procedure}

When subjects arrived for the experiment, a bite bar was prepared that served to eliminate head movements. Subjects were told to read sentences for meaning as their eye movements were recorded and that they might sometimes notice display changes 
Table 1

Gaze Durations (in Milliseconds) on the Target Word and First-Fixation Durations (in Parentheses) as a Function of Prime Duration and Prime Type in Phonological, Semantic, and Orthographic Priming Conditions

\begin{tabular}{|c|c|c|c|c|}
\hline Prime Duration & \multicolumn{2}{|c|}{ Prime Type } & Difference & $\begin{array}{l}p \text { value } \\
\text { in } t \text { test }\end{array}$ \\
\hline \multicolumn{5}{|c|}{ Phonological Priming } \\
\hline & $\mathrm{H}$ & $\mathrm{OC}$ & $\mathrm{OC}-\mathrm{H}$ & \\
\hline $29 \mathrm{msec}$ & $358(334)$ & $399(371)$ & $41(37)$ & $.010(.031)$ \\
\hline $32 \mathrm{msec}$ & $367(341)$ & $398(369)$ & $31(28)$ & $.017(.052)$ \\
\hline $35 \mathrm{msec}$ & $349(332)$ & $394(356)$ & $45(24)$ & $.012(.174)$ \\
\hline $38 \mathrm{msec}$ & $375(352)$ & $370(349)$ & $-5(-3)$ & $.668(.811)$ \\
\hline $41 \mathrm{msec}$ & $371(342)$ & $376(355)$ & $5(13)$ & $.710(.306)$ \\
\hline \multicolumn{5}{|c|}{ Semantic Priming } \\
\hline & $\mathrm{R}$ & $\mathrm{U}$ & $U-R$ & \\
\hline $29 \mathrm{msec}$ & $377(346)$ & $382(352)$ & $5(6)$ & $.717(.692)$ \\
\hline $32 \mathrm{msec}$ & $375(351)$ & $412(377)$ & $37(26)$ & $.008(.056)$ \\
\hline $35 \mathrm{msec}$ & $384(363)$ & $396(364)$ & 12 (1) & $.382(.936)$ \\
\hline $38 \mathrm{msec}$ & $388(378)$ & $401(378)$ & $13(0)$ & $.383(.970)$ \\
\hline $41 \mathrm{msec}$ & $381(359)$ & $394(371)$ & $13(12)$ & $.119(.262)$ \\
\hline \multicolumn{5}{|c|}{ Orthographic Priming } \\
\hline & $\mathrm{S}$ & D & $D-S$ & \\
\hline $29 \mathrm{msec}$ & $358(343)$ & $393(368)$ & $35(25)$ & $.016(.077)$ \\
\hline $32 \mathrm{msec}$ & $346(319)$ & $403(362)$ & $57(43)$ & $.001(.007)$ \\
\hline $35 \mathrm{msec}$ & $354(324)$ & $411(382)$ & $57(58)$ & $.001(.001)$ \\
\hline $38 \mathrm{msec}$ & $345(317)$ & $406(377)$ & $61(60)$ & $.001(.001)$ \\
\hline $41 \mathrm{msec}$ & $337(325)$ & $396(366)$ & $59(41)$ & $.001(.009)$ \\
\hline
\end{tabular}

Note- $\mathrm{H}$, homophone; OC, orthographic control; $\mathrm{R}$, related; $U$, unrelated; S, similar; $\mathrm{D}$, different.

(i.e., they might see something flash) while they read, but that they should try to read as normally as possible. They were told that they would be given yes/no comprehension questions about some of the sentences. The initial calibration of the eyetracking system generally required about $5 \mathrm{~min}$. Prior to the presentation of each sentence, a series of five calibration boxes appeared on the monitor, extending from the first to the last character position of a full line of text During a calibration check, subjects were instructed to look at each box to verify the accurate recording of eye position (with an additional moving red box representing the computed eye position)

After the initial calibration, each subject read 10 practice trials to become familiar with the procedure. Prior to each trial, the experimenter checked to make certain that the eyetracking system was accurately tracking the subject (i.e., the subject looked at the fixation boxes after each trial). If calibration was inaccurate, the subject was recalibrated. If calibration was accurate, subjects were asked to look at the first box (the first character position of the sentences), and then the new sentence was presented. When the subject finished reading, he/she pressed a button that blanked the monitor. Then, either a yes/no comprehension question was given or five boxes were given for the start of the next trial. After the practice trials, each subject read 150 experimental sentences. Questions were asked on approximately one fourth of the trials: Subjects responded to the question by pressing a left (yes) or a right (no) button in a response box (given to the subject when he/she was seated in front of the monitor).

An invisible boundary located just before the last letter of the word preceding the target word was established for each sentence (Figure 1). When the sentence was initially presented on the monitor, a string of random letters occupied the target position. When a saccade crossed over the invisible boundary, the random letters were replaced with a prime word (see Rayner, 1975, for a fuller description of the boundary technique). Because the change took place during the saccade (when vision is suppressed), subjects did not notice it. The prime word remained in the target location for a specified duration $(29,32,35,38$, or $41 \mathrm{msec}$, measured from the onset of the fixation, not from when the eye crossed the boundary) and was then replaced by the target word. This second display change, which occurred during a fixation, was often noticed by subjects as a brief flicker. The target word remained in place while subjects finished reading the sentence. Because all display changes were delayed until the electron beam finished replotting the text, the actual prime durations were up to $6.25 \mathrm{msec}$ longer than nominal prime duration, which was the signal to make the display change. For example, the actual prime interval could range from 29 to about $35 \mathrm{msec}$ for the nominal 29-msec prime duration (because the signal to replace the prime with the target could occur at any point during the $6.25 \mathrm{msec}$ needed to "paint" the screen). At the end of the experiment, subjects were asked about what they noticed about the display changes. They reported noticing that something was happening when they fixated the target word (i.e., when the prime changed to the target) most of the time, but they were rarely able to identify the prime.

\section{RESULTS}

Data were excluded from the analyses for any of the following reasons: (1) There was a track loss; (2) the reader skipped over the target word, which included the space before the word and the word itself; (3) the eyes triggered the boundary but remained on the word before the target (usually the last letter of this word); (4) the onset of the prime did not coincide with the onset of the fixation; (5) the first fixation on the target word was less than $150 \mathrm{msec}$, or a first-pass fixation (one not resulting from a regression) was greater than $900 \mathrm{msec}$ (these values include the prime duration); and (6) a first-pass fixation on the target word was the last fixation recorded in the sentence. In addition to the data of the 30 subjects analyzed below, the data of 3 subjects were excluded because they did not reach a $60 \%$ usable data criterion (a criterion applied in previous fast-priming studies). The mean percentage of usable data across the 30 subjects was $79 \%$, and the mean percentage of their correct responses for yes/no comprehension questions was $92 \%$, indicating little problem in understanding the sentences.

We analyzed both the gaze duration and first-fixation duration on the target word (Table 1). Gaze duration is the sum of all consecutive fixations on a word prior to an eye movement to another word and first-fixation duration is the duration of the first fixation on a target word, independent of the number of fixations made. (In both cases, only trials on which the word is not initially skipped are counted in the means.) In the table, we subtracted the prime duration from the gaze durations and first-fixation durations so that these measures assess the time the target region is fixated after the target word appears. Since the pattern of results was quite consistent for the two measures (Table 1), we will focus on the gaze-duration measure for ease of exposition.

\section{Phonological Priming}

Phonological priming effects are indicated by the difference in gaze durations on targets between the ortho- 
graphic control $(\mathrm{OC})$ and homophone $(\mathrm{H})$ prime conditions. Analyses of variance (ANOVAs) based on subject $\left(F_{1}\right)$ and item variability $\left(F_{2}\right)$ were conducted on the gaze durations using prime type and prime duration as withinsubject variables. A 2 (prime type: $\mathrm{H}, \mathrm{OC}) \times 5$ (prime duration: $29,32,35,38,41 \mathrm{msec}$ ) ANOVA yielded a $24-$ msec main effect of prime type $\left[F_{1}(1,29)=20.54, M S_{\mathrm{e}}=\right.$ $\left.1,994, p<.001 ; F_{2}(1,49)=7.11, M S_{\mathrm{e}}=10,047, p<.01\right]$, indicating the presence of phonological priming early in a fixation during reading. The interaction between prime duration and prime type was marginally significant $\left[F_{1}(4,116)=2.38, M S_{\mathrm{e}}=3,205, p=.056 ; F_{2}(4,196)=\right.$ $\left.2.39, M S_{\mathrm{e}}=8,624, p=.052\right]$, but more diagnostically, the linear trend (over duration) of the priming effect was significant $\left[F_{1}(1,29)=7.48, M S_{\mathrm{e}}=2,404, p<.02 ; F_{2}(1,49)=\right.$ $4.39, M S_{\mathrm{e}}=9,015, p<.05$ ], indicating that phonological priming occurred for the shorter prime durations but not for the longer ones. This was reinforced by $t$ tests showing that significant phonological priming effects were obtained at the 29-, 32-, and 35-msec prime durations ( $p$ s $<$ .02 ), but not at the 38- and 41-msec prime durations $(p s>.5)$. The main effect of prime duration was not significant $(F \mathrm{~s}<1)$.

After conducting the experiment, we discovered that the orthographic match of the primes to the targets, while good, was not perfect. To evaluate the amount of orthographic mismatch, we used two measures: (1) strict- the number of letters differing between target and prime where "matches" count only if the letters are in the same position; and (2) lenient - the number of letters differing between target and prime where "matches" count regardless of position in the word. (For example, for the pair gait-gate, the strict score is 2 and the lenient score is 1.) In fact, the mean difference between homophones and controls was 0.14 on the strict scoring measure and 0.04 on the lenient scoring measure (both measures slightly favoring the homophones). To determine whether these slight differences could predict homophone priming, we took the mean homophone priming effect averaged over the 29-, 32-, and 35-msec prime durations for each of the 50 items and attempted to predict them (using a regression analysis) with (1) the difference in the strict score and (2) the difference in the lenient score between homophone and control for that item. The outcome of the regression analysis was clear. The intercept of the regression, which reflects the "true homophone priming effect" when both these confounds are eliminated, was $41 \mathrm{msec}$ $[t(47)=3.70, p<.001]$, and neither predictor was close to significant (both $t \mathrm{~s}<1$ ). Hence, we think it is quite unlikely that our homophone priming effect was due to uncontrolled orthographic differences.

\section{Semantic Priming}

Semantic priming effects are indicated by the difference in gaze durations on targets between semantically related $(\mathrm{R})$ and unrelated $(\mathrm{U})$ prime conditions. A 2 (prime type: R, U) $\times 5$ (prime duration: $29,32,35,38,41 \mathrm{msec}$ ) ANOVA yielded a 16-msec main effect of prime type $\left[F_{1}(1,29)=9.34, M S_{\mathrm{e}}=2,054, p<.005 ; F_{2}(1,49)=9.57\right.$, $\left.M S_{\mathrm{e}}=4,311, p<.005\right]$, indicating the presence of semantic priming early in a fixation during reading. However, the results of paired $t$ tests showed that the priming effect was significant only at the $32-\mathrm{msec}$ prime duration $(p<.01$; the $p$ s were greater than 1 for the other prime durations). Notably, the priming effect at the shortest prime duration $(29 \mathrm{msec})$ was only $5 \mathrm{msec}$. This is in contrast with the 41-msec phonological priming effect at the 29msec prime duration. The main effect of prime duration was not significant $\left(F_{\mathrm{S}}<1\right)$.

\section{Orthographic Priming}

Orthographic priming effects are indicated by the difference in gaze durations on targets between orthographically similar (S) and orthographically different (D) prime conditions. A 2 (prime type: S, D) $\times 5$ (prime duration: $29,32,35,38,41 \mathrm{msec}$ ) ANOVA yielded a $53-\mathrm{msec}$ main effect of prime type $\left[F_{1}(1,29)=57.07, M S_{\mathrm{e}}=3,832\right.$, $\left.p<.001 ; F_{2}(1,49)=46.28, M S_{\mathrm{e}}=6,893, p<.001\right]$, indicating the presence of orthographic priming early in a fixation during reading. More specifically, the results of paired $t$ tests showed that a significant orthographic priming effect was obtained at all prime durations $(p \mathrm{~s}<.02)$. Neither the main effect of prime duration nor the interaction between prime type and prime duration reached significance $\left(F_{\mathrm{s}}<1\right)$. Interestingly, the linear component of the interaction was marginally significant $\left[F_{1}(1,29)=\right.$ $2.97, M S_{\mathrm{e}}=1,394, p=.095$ ], suggesting that the orthographic priming effect increased with longer prime durations; however, this effect was not significant over items $\left(F_{2}<1\right)$.

\section{DISCUSSION}

The principal results of the study were as follows: (1) Significant phonological priming was obtained at all prime durations between 29 and $35 \mathrm{msec}$; (2) significant semantic priming was obtained only at the $32-\mathrm{msec}$ prime duration; and (3) significant orthographic priming was obtained at all prime durations ( $29-41 \mathrm{msec}$ ). The results of the present study are consistent with previous studies of fast priming during reading (Lee et al., 1999; Rayner et al., 1995; Sereno, 1995; Sereno \& Rayner, 1992), and provide further evidence for the activation of phonological, semantic, and orthographic codes early during a fixation in reading. More importantly, they expand our knowledge of the relative time course of these priming effects. First, with phonological priming, earlier studies obtained phonological priming only at one prime duration (using bigger differences between prime durations). The present study indicates that significant phonological priming occurs in a reasonably wide "window" of prime durations. Second, our results indicate that the window 
for phonological priming is larger than that for semantic priming, and, most importantly, occurs for shorter prime durations than semantic priming. These results thus suggest that phonological codes are activated at least as rapidly as semantic codes during a fixation in reading.

Is access to phonological codes presemantic or postsemantic? Probably the most important finding of the present results is that phonological codes of a word can be activated earlier than the semantic codes. Needless to say, this finding rules out the hypothesis that phonological coding is postsemantic, in the sense that phonological codes are necessarily activated only after semantic coding. This leaves open the question of whether access to the phonological code of a word is necessary for access to its meaning or whether access to its phonological codes and its semantic codes occur in parallel. As indicated, phonological priming occurred not only earlier than semantic priming, but also in a broader temporal "window." There are two possible accounts for this pattern of data. One is that the speed of access to phonological codes is more varied than that to semantic codes, which would imply that access to the two types of codes is in parallel. The other account is that phonological codes are activated as rapidly as $29 \mathrm{msec}$, but that their activation is sustained longer than semantic codes, allowing a significant phonological priming effect even when semantic priming has dissipated. The latter account could be consistent with either a serial (i.e., phonological coding first) or a parallel account of the relation between phonological and semantic coding of printed words. Thus, the data are consistent either with presemantic activation of phonological codes or with activation of both codes in parallel (possibly interacting with each other).

Are phonological codes that are extracted early in a fixation during reading lexical or prelexical? The present study did not address this issue directly. However, the results of a previous fast-priming study indicated that the early activation of phonological codes is strongly influenced by lexical processing. Lee et al. (1999) found a homophone priming effect as early as at a 32-msec prime duration, but found no pseudohomophone priming effect even at a 42-msec prime duration (the longest prime duration in their study). Furthermore, Lee et al. found that homophone priming occurred only when the word primes were high frequency. These results appear to indicate that the phonological codes evoked early in word processing are not prelexical. Other studies, however, employing other paradigms, suggest that there is relatively early prelexical phonological coding. Perfetti and Bell (1991), for example, showed that a pseudohomophone could prime the identification of the target word at prime durations greater than or equal to $45 \mathrm{msec}$. This suggests that activation of phonological codes unsupported by lexical activation may occur, but the time course for such activation might be slower than for phonological codes facilitated by significant lexical input. Thus, perhaps the safest conclusion that can be drawn is that lexical activation and phonological activation occur in parallel, but that lexical activation quickly guides the process of phonological coding.

Phonological and semantic priming versus orthographic priming. One clear distinction between the phonological and semantic priming patterns and the orthographic priming pattern is that phonological and semantic priming have a narrower temporal window than orthographic priming: Whereas orthographic priming occurred at all prime durations (29-41 $\mathrm{msec}$ ), phonological priming occurred at the 29 to $35 \mathrm{msec}$ prime durations and semantic priming occurred only at the $32-\mathrm{msec}$ prime duration. In addition, orthographic priming appeared to linearly increase with time, although only marginally so.

This difference in pattern has two important implications. First, it indicates that orthographic priming is distinct from phonological priming in spite of possible confoundings between orthographic and phonological similarity. For example, house as an orthographic prime of horse is not only orthographically similar but also phonologically similar. The data of Rayner et al. (1995) perhaps make the distinction between orthographic and phonological priming even more clearly. In that study, as in the present one, there was a large orthographic priming effect at all prime durations; however, there was no phonological priming effect at the shorter prime durations, but about as large a phonological priming effect at the longest prime duration (which was about equal to the middle prime durations of the present experiment). This pattern makes little sense if both priming effects were due to orthography, because any possible uncontrolled difference in orthographic similarity to the target between the homophone and its orthographic control would be much smaller than the large difference in orthographic similarity to the target between the orthographic primes and the dissimilar controls.

Second, the fact that phonological and semantic priming seem to disappear at longer intervals suggests that, for some reason, the homophone and semantic primes are being inhibited in ways that the orthographic primes are not. One possibility is that orthographic codes are longer lived than either phonological or semantic codes. While this is a possibility, it seems intuitively implausible, because the purpose of reading is to code for meaning and there seems to be agreement that phonological codes serve an important short-term memory function in reading.

Instead, we think that something like an activationverification model provides a reasonably plausible account of the data pattern. We will adopt as our framework the model first proposed by Van Orden (1987), in which a strictly serial two-stage process is posited. (However, we think that a less strictly serial interactive model such as that of Van Orden et al., 1988, may make similar predictions.) In the first stage, the phonological code is accessed, which triggers a second "spelling check" stage in which the orthographic representation of the stimulus is compared with the orthographic representations of the various stimuli consistent with this phonological representation to se- 
lect the appropriate stimulus. We now need to make the following additional assumptions. First, an orthographically similar prime (either a homophone or nonhomophone) will facilitate the early stages of accessing the phonological code by providing greater support for the component letters. This accounts for the orthographic priming effect. Second, a lasting orthographic representation of the prime that can influence the verification process takes time to build up and, if the prime is too short, such an orthographic representation will not long survive the onset of the target. This lasting orthographic representation of the prime is potentially interfering because it will compete with the orthographic representation of the target. However, if one assumes that only orthographic representations within the set of homophones are checked in the verification process, then the orthographic representation of the orthographic prime will be outside this "candidate set" and thus not provide significant competition, whereas the orthographic representation of the homophone prime will be in the candidate set and thus provide substantial competition.

To summarize, this model views the orthographic code of orthographically similar primes as having both facilitative and inhibitory effects. In the early stages of processing, the effect is facilitative, helping to activate the phonological code; in late stages, the effect is inhibitory, but only if the orthographic code of the prime is within the "candidate set" being checked out. This model thus predicts that orthographically similar primes (whether homophones or not) will facilitate relative to orthographically dissimilar primes for short prime durations because the component letters start to activate a phonological representation. (This was observed in prior fast-priming experiments, where homophone primes were directly compared with orthographically dissimilar primes, and it is implicit in the present experiment.) At middle prime durations, when the phonological representation is fully formed, the homophone will have an advantage over the orthographically similar nonhomophone because it is a better prime for the phonological code. At longer prime durations, the verification process then puts homophones at a disadvantage to the orthographically similar nonhomophones (as indicated above), and one would expect the advantage of the homophones over orthographic controls to disappear, or possibly even undergo a reversal. (In fact, both patterns have been observed in prior experiments.)

That explanation, unmodified, of course cannot explain why semantic priming also disappears at longer priming intervals. The simplest modification would be to suggest that not only does the candidate set include the orthographic representations of all homophones, but that orthographic representations of semantic associates also become activated. This could occur if the semantic priming effect is mutual (i.e., the target activates the prime as well as the prime activating the target).

Finally, we need to discuss two studies that reported data on the relative time courses of phonological, semantic, and orthographic coding that are somewhat in- consistent with ours. First, Perfetti and Tan (1998), in a priming study in which Chinese subjects named Chinese characters, found that activation of codes occurred in the following order: orthographic, then phonological, and lastly semantic. Orthographic priming was first obtained at the 43-msec duration, whereas phonological priming was first obtained at the $57-\mathrm{msec}$ duration, and semantic priming at the $85-\mathrm{msec}$ duration. In addition, the orthographic priming changed to inhibition at the 57 - and 85 msec durations, whereas phonological priming also occurred at the $85-\mathrm{msec}$ duration. Second, Ferrand and Grainger (1994), in a lexical decision task in French, observed orthographic priming at a 29 -msec prime duration but no phonological priming at that duration. Ferrand and Grainger, like Perfetti and Tan, observed the disappearance of orthographic priming with longer durations of 43 and $57 \mathrm{msec}$. The pattern of these studies indicates that orthographic priming precedes phonological priming, and then disappears rapidly, presumably faster than phonological priming. The precedence of orthographic priming over phonological priming is consistent with earlier findings from the fast-priming paradigm that have shown that orthographic priming but no phonological priming was obtained at the 24-msec prime duration (Rayner et al., 1995). The faster decrease of orthographic priming relative to phonological priming, however, seems inconsistent with our data as well as earlier findings from the fastpriming paradigm (Lee et al., 1999), which show that orthographic priming was sustained longer than phonological priming.

There are several possibilities for this inconsistency. One is that variability in the experimental situation, such as differences in language (Chinese, French, English), lexicality of stimuli (real words or nonwords), or task paradigms (isolated word processing or reading in context), leads to the difference. Another is that the degree of phonological similarity of an orthographic prime to the target word differed across studies and may have led to different patterns in the time course of orthographic priming. The orthographic primes in our study appear to be phonologically more similar to the target words than those used by Perfetti and Tan (due to the greater ease of unconfounding orthography and phonology in Chinese characters). In the Ferrand and Grainger (1994) study, which assessed priming at longer prime durations, all related primes were homophones and orthographic effects were assessed by comparing orthographically similar homophone primes (e.g., mert-mere) with orthographically less similar homophone primes (e.g., mair-mere). Earlier, to account for a narrower temporal window of phonological priming than orthographic priming in our data, we suggested that only orthographic representations within the set of homophones of the target were checked in the verification process. The same logic can apply to the findings of Ferrand and Grainger: Because the prime was a homophone, the verification process would be slowed at longer prime durations, resulting in a disappearance of a difference between the two homophones. However, because both 
homophones were quite a bit more orthographically similar to the target than the control stimulus used to assess the homophonic priming effect (e.g., toul-mere), the "phonological" priming at longer prime durations may be like our orthographic priming effect. Then, how do we explain the inconsistency between our data and those of Perfetti and Tan (1998), in which target words were less phonologically overlapped with their orthographic primes relative to our targets, thus unlikely to be inhibited during the verification process? One plausible account is that orthographic priming may be influenced by phonological similarity in such a way that without the accompaniment of some degree of phonological similarity, orthographic priming cannot be sustained for very long. This is highly speculative, but provides a possible way to reconcile the slightly different patterns of orthographic priming in Perfetti and Tan's study and our study.

We clearly need to understand more about the time course of activation of orthographic, phonological, and semantic codes during reading. Nevertheless, we think the present data make several important points. First, phonological codes play an important role in silent reading because they are extracted early during a fixation. Second, the extraction of these phonological codes from printed words is at least as rapid as the extraction of meaning. Why does phonology play a role in silent reading? At a strategic level, phonological information should be useful in integrating the meaning of text; among other things, auditory sensory memory is sustained longer and less effortfully than visual sensory memory. Moreover, because language is fundamentally auditory, it may be impossible if not difficult to inhibit phonological coding of visual language. A third possibility (Share, 1999) is that constructing a phonological code is vital for being able to rapidly construct an orthographic representation, which is presumably a symbolic construction from an essentially meaningless but complex visual stimulus.

\section{REFERENCES}

Baddeley, A. D.. Eldridge, M., \& Lewis, V. (1981). The role of subvocalization in reading. Quarterly Journal of Experimental Psychology, 33A, 439-454.

Bauer, D. W., \& Stanovich, K. E. (1980). Lexical access and the spelling-to-sound regularity effect. Memory \& Cognition, 8, 424. 432.

Daneman, M., Reingold, E. M., \& Davidson, M. (1995). Time course of phonological activation during reading: Evidence from eye fixations. Journal of Experimental Psychology: Learning. Memory. \& Cognition, 21, 884-898.

FERRAND, L., \& Grainger, J. (1994). Effects of orthography are independent of phonology in masked form priming. Quarterly Journal of Experimental Psychology, 47A, 365-382.

Forster, K. I., \& DAVIS, C. (1984). Repetition priming and frequency attenuation in lexical access. Journal of Experimental Psychology. Learning, Memory, \& Cognition, 10, 680-698.

Francis. W. N., \& KuČERA, H. (1982). Frequency analysis of English usage: Lexicon and grammar. Boston: Houghton Mifflin.

HoBBS. J. B. (1986). Homophones and homographs: An American dictionary. Jefferson, NC: McFarland.

JARED, D. (1997). Spelling-sound consistency affects the naming of high-frequency words. Journal of Memory \& Language, 36, 505-529.

KLEIMAN, G. M. (1975). Speech recoding in reading. Journal of Verbal Learning \& Verbal Behavior. 14, 323-339.
Lee, Y., Binder, K. S., Kim, J., Pollatsek, A., \& Rayner, K. (1999) Activation of phonological codes during eye fixations in reading. Journal of Experimental Psychology: Human Perception \& Performance, 25, 948-964.

LESCH, M. F., \& Pollatsek, A. (1998), Evidence for the use of assembled phonology in accessing the meaning of printed words. Journal of Experimental Psychology: Learning, Memory, \& Cognition, 24, 573-592.

Lukatela, G., \& Turvey, M. T. (1994). Visual lexical access is initially phonological: 1 . Evidence from associative phonological priming by homophones and pseudohomophones. Journal of Experimental Psychology: General, 123, 107-128.

Perfetti, C. A., \& Bell, L. C. (1991). Phonemic activation during the first $40 \mathrm{~ms}$ of word identification: Evidence from backward masking and priming. Journal of Memory \& Language, 30, 473-485.

Perfetti, C. A., Bell, L. C., \& Delaney, S. M. (1988). Automatic (prelexical) phonetic activation in silent word reading: Evidence from backward masking. Journal of Memory \& Language, 27, 59-70.

Perfetti, C. A., \& TAN, L. H. (1998). The time course of graphic, phonological, and semantic activation in Chinese character identification. Journal of Experimental Psychology: Learning, Memory. \& Cognition, 24, 101-118.

Pollatsek, A., Lesch, M., Morris, R. M., \& Rayner, K. (1992). Phonological codes are used in integrating information across saccades in word identification and reading. Journal of Experimental Psychology: Human Perception \& Performance, 18, 148-162.

Pollatsek, A., Rayner, K., \& Lee, H.-W. (in press). Phonological coding in word perception and reading. In A. Kennedy, R. Radach, D. Heller, \& J. Pynte (Eds.), Reading as a perceptual process. Amsterdam: Elsevier.

Postman, L., \& KepPel, G. (1970). Norms of word association. New York: Academic Press.

RAYNER, K. (1975). The perceptual span and peripheral cues in reading. Cognitive Psychology, 7, 65-81.

Rayner, K., Pollatsek, A., \& Binder, K. (1998). Phonological codes and eye movements in reading. Journal of Experimental Psychology: Learning, Memory, \& Cognition, 24, 476-497.

Rayner, K., Sereno, S. C., Lesch, M. F., \& Pollatsek, A. (1995) Phonological codes are automatically activated during reading: Evidence from an eye movement priming paradigm. Psychological Science, 6, 26-30.

Seidenterg, M. S., Waters, G. S., Barnes, M. A., \& Tanenhaus, M. K. (1984). When does irregular spelling or pronunciation influence word recognition? Journal of Verbal Learning \& Verbal Behavior, 23, 383-404.

SERENO, S. C. (1995). The resolution of lexical ambiguity: Evidence from an eye movement priming paradigm. Journal of Experimental Psychology: Learning, Memory, \& Cognition, 21, 285-294.

SERENO, S. C., \& RAYNER, K. (1992). Fast priming during eye fixations in reading. Journal of Experimental Psychology: Human Perception \& Performance, 18, 173-184.

SHARE, D. (1999). Phonological recoding and orthographic learning: A direct test of the self-teaching hypothesis. Journal of Experimental Child Psychologv, 72, 95-129.

Slowiaczek, M. L., \& Clifton, C. (1980). Subvocalization and reading for meaning. Journal of Verbal Learning \& Verbal Behavior, 19 , 573-582.

TAFT, M. (1991). Reading and the mental lexicon. Hove, U.K.: Erlbaum.

Treiman, R. A., Freyd, J. J., \& Baron, J. (1983). Phonological recoding and use of spelling sound rules in reading of sentences. Journal of Verbal Learning \& Verbal Behavior, 22, 682-700.

VAN ORDEN, G. C. (1987). A ROWS is a ROSE: Spelling, sound, and reading. Memory \& Cognition, 15, 181-198.

VAn Orden, G. C., Johnston, J. C., \& Hale, B. L. (1988). Word identification in reading proceeds from spelling to sound to meaning. Journal of Experimental Psychology: Learning, Memory, \& Cognition, 14, 371-386.

\section{NOTES}

1. The prime durations cited here are "nominal" prime durations, since one cannot completely control the duration of the prime in this 
paradigm on a raster-scanning monitor. Such control is impossible because the prime duration is an interval between an action of the subject (the beginning of a fixation), which is random with respect to the screen location of the raster device, and the subsequent display change. The nominal durations are the interval between the beginning of the fixation and when the computer indicates a display change should be made. The actual display change then occurs within one raster scan of the nominal duration (for our experiments, within about $6 \mathrm{msec}$ ).

2. The prime durations at which semantic priming was observed are likely to depend on the characteristics of the display monitor, which differed across experiments (see Sereno, 1995).
3. There are arguments that beach is orthographically more similar to beech than bench due to the higher similarity between $e a$ and $e e$, which can represent the same sound (Taft, 1991). These arguments are called into question, however, by the findings of Lesch and Pollatsek (1998) that the interference effect for cowl (false homophone of coal) over the orthographic control coil was significantly smaller than that for rein (true homophone of rain) over the orthographic control ruin. In contrast, by Taft's arguments, the interference effects would be expected to be the same because -owl and -oal should be as orthographically similar as -ain and -ein. (See Pollatsek, Rayner, \& Lee, in press, for a more detailed discussion and analysis of the Lesch \& Pollatsek data.)

\begin{tabular}{|c|c|c|}
\hline \multicolumn{3}{|l|}{ APPENDIX } \\
\hline \multirow[b]{2}{*}{ Experimental Sentences (Target Italicized) } & \multicolumn{2}{|c|}{ Primes } \\
\hline & $\mathrm{H}$ & $\mathrm{OC}$ \\
\hline \multicolumn{3}{|l|}{ Phonological Priming } \\
\hline We saw the beautiful altar inside the church. & alter & after \\
\hline This bird prefers beech trees for nesting. & beach & bench \\
\hline John sneezed and loudly blew his nose all day. & blue & belt \\
\hline He put his emergency brake on just in time. & break & bride \\
\hline All the prison cells were full. & sells & calls \\
\hline He gave his last cent to charity. & sent & went \\
\hline The laundry chute was filled with clothes. & shoot & shine \\
\hline Writers must always cite their references. & site & city \\
\hline Sally sat in a momentary daze feeling the sunshine. & days & dark \\
\hline There was a lot of shiny dew in the ground. & due & die \\
\hline Elizabeth mixed the colorful dye with water. & die & due \\
\hline We know that the cheap fare was more than reasonable. & fair & farm \\
\hline It was an amazing feat of skill. & feet & fear \\
\hline The cat had a green flea collar on its neck. & flee & flat \\
\hline His slow gait deceived everyone. & gate & gain \\
\hline The recipe said to finely grate the cheese finely. & great & grant \\
\hline The slow tortoise and the quick hare were sick. & hair & hard \\
\hline We decided to quickly haul the wood to the house. & hall & half \\
\hline Mom said the cut would heal in a few days. & heel & heat \\
\hline There was a napping lone rider on the trail. & loan & lean \\
\hline He gets irritated by junk mail and fliers. & male & maid \\
\hline Oddly, he was the only male in the bar. & mail & melt \\
\hline The long mane of the lion was ugly. & main & meal \\
\hline We cooked the fresh meat on the grill. & meet & mean \\
\hline The boy received a large medal for his bravery. & metal & model \\
\hline We heard the elderly miner was still missing. & minor & miles \\
\hline I hate to eat slimy mussels at dinner. & muscles & muzzles \\
\hline He tripped on the metal pail on the porch. & pale & palm \\
\hline We knew that the window pane was broken. & pain & plan \\
\hline We all hope for world peace in the world. & piece & place \\
\hline Stanley prefers pears to peaches. & pairs & prays \\
\hline The notebook was pretty plain and shabby. & plane & plant \\
\hline He couldn't see any single pore on his palm. & poor & peer \\
\hline We watched the last reel of the movie. & real & role \\
\hline The leather rein cut into my hands. & rain & ruin \\
\hline They felt it was their right to protest. & write & rifle \\
\hline John saw the girls sail on the lake. & sale & salt \\
\hline There was a great sale at the dress shop. & sail & seat \\
\hline She thought that the cotton seam had broken. & seem & same \\
\hline People who sincerely seek wealth often find it. & sick & $\sin \mathrm{k}$ \\
\hline He knew the correct sine of a right angle is 1 . & sign & size \\
\hline Everyone seemed to cautiously stare at us. & stair & stars \\
\hline It is easy to quietly steal apples from him. & steel & steak \\
\hline The bedroom suite was very exp & sweet & suits \\
\hline
\end{tabular}


APPENDIX (Continued)

\begin{tabular}{|c|c|c|}
\hline \multirow[b]{2}{*}{ Experimental Sentences (Target Italicized) } & \multicolumn{2}{|c|}{ Primes } \\
\hline & $\mathrm{H}$ & $\mathrm{OC}$ \\
\hline $\begin{array}{l}\text { The bright sun seemed to fill the sky. } \\
\text { The city seemed to always teem with warmth. } \\
\text { The prince will ascend the king's throne very soon. } \\
\text { The peddler's wares included a brass pot. } \\
\text { Jeff was quite weak from his illness. } \\
\text { Her hands were worn from too many dishes. }\end{array}$ & $\begin{array}{l}\text { son } \\
\text { team } \\
\text { thrown } \\
\text { wears } \\
\text { week } \\
\text { warn }\end{array}$ & $\begin{array}{l}\sin \\
\text { term } \\
\text { throat } \\
\text { waves } \\
\text { walk } \\
\text { word }\end{array}$ \\
\hline Semantic Priming & $\mathrm{R}$ & $\mathrm{U}$ \\
\hline Harry sold the wooded acre to his brother. & land & step \\
\hline George served me a delicious apple for dessert. & fruit & track \\
\hline On holidays our kindly aunts usually visit. & uncle & chest \\
\hline Al can't separate beer from gin drinkers. & wine & clay \\
\hline Jane wore a fancy black jacket to the party. & white & field \\
\hline I trusted that the shiny blade was sharp. & knife & youth \\
\hline I noticed a bleached bone beside the path. & skin & salt \\
\hline Grandma got attached to the sleepy cats quickly. & dogs & beds \\
\hline We needed another chair for the meeting. & table & piece \\
\hline Greg had never seen the large cobra in action. & snake & brain \\
\hline She needed the proper drill for the job. & tools & souls \\
\hline There were several eggs that we had collected. & hens & risk \\
\hline Gary took the chemistry exam four days late. & test & tree \\
\hline Doug was surprised at the immense gain from the business. & loss & poem \\
\hline Some say a real nice girl doesn't swear. & boys & laws \\
\hline Dr. Beck's elaborate graph was impressive. & chart & flame \\
\hline We visited Mark's grave his morning. & death & class \\
\hline Karen wore a flowery green skirt to class. & grass & judge \\
\hline We saw the young groom go into the bathroom. & bride & shift \\
\hline Tight quarters produced hate and discord. & love & club \\
\hline I hung their hats in the vestibule. & coat & luck \\
\hline We visited the elderly judge in his chambers. & court & class \\
\hline Many of the small lambs were lost in the storm. & sheep & brick \\
\hline Roy noticed Sue's legs for the first time. & arms & wall \\
\hline The finest linen would be her dowry. & cloth & noise \\
\hline I'd love a leisurely meal for a change. & food & game \\
\hline Aunt Rose lost her grocery money at the races. & purse & stain \\
\hline They said that the funny movie was worth seeing. & films & items \\
\hline The dirty mugs were a real eyesore. & cups & guys \\
\hline Jeff claims that the notorious navy is a hassle. & army & lady \\
\hline Kathy looked for a sharp needle in the room. & thread & hazard \\
\hline We thought his bloody nose was broken. & eyes & area \\
\hline It was an interesting novel to read. & story & union \\
\hline Most of the diligent nurses were very busy. & doctor & action \\
\hline Diane forgot which page she was on. & book & jobs \\
\hline Phil lost his favorite pants at the pool party. & shirt & screw \\
\hline Judy brought several pies to the reunion. & cake & rose \\
\hline For us kids, the small pond was a great hangout. & lake & card \\
\hline The story of the gypsy queen was stirring. & kings & deals \\
\hline Surprisingly, our little ship survived the storm. & boat & note \\
\hline It is sometimes hard to soundly sleep at night. & dream & index \\
\hline They found their socks behind the door. & shoes & fight \\
\hline Sometimes, the irritating sound wakes me up. & music & views \\
\hline Far from city lights, the beautiful star sparkles. & moon & vote \\
\hline The rooster's tail was tattered. & head & form \\
\hline My cousin's teeth were very crooked. & mouth & doubt \\
\hline Sally likes the ferocious tiger best in the circus. & lions & bowls \\
\hline The cold had made Tom's toes red and numb. & feet & need \\
\hline We love our small town because it's part of us. & city & fact \\
\hline A good waltz always gets Charlie excited. & dance & sight \\
\hline
\end{tabular}




\section{APPENDIX (Continued)}

Experimental Sentences (Target Italicized)
Orthographic Priming

The hero's acts made him famous.

The dying man saw a little angel in the room. He threw the soccer ball across the field.

Kelly's favorite band was playing.

The beautiful blond singer was late.

We had a small chance to win the game.

She touched his right cheek with her hand.

Ann can usually count backwards very well.

Jill put the jeweled crown on the king's head.

The dreadful curse frightened everyone.

It was a beautiful dawn yesterday.

He had been a college dean for twenty years.

The last decade brought many changes.

You must have desire to succeed.

He put a used disk in the computer.

They were experts on baseball.

His family farm is not making money.

He put the important file inside the desk drawer.

He mixed the wheat flour and water together.

He was in a different guise than we expected.

Trisha rode her favorite horse to the store.

Jake had been my only idol for many years.

The country lane was very narrow.

He put an ugly mask over his face.

He had the strong notion that he was right.

It is hard to get a legal patent on some things.

You must put the electrical plug in the socket.

He called the local police emergency number.

Some people have great pride in their pets.

We thought he was a complete quack right away.

She knew that the true root of evil was money.

You can get a free sample at the store.

She knew there was a strange scent in the air.

The latest score of the game was not available.

The object had a strange shape and size.

We could see the vicious shark in the water.

There were many sheep on the farm.

The ancient shop was very pleasant.

His final shot hit the target.

Thomas examined the ancient skull in the grave.

We saw the famous statue on the mantle.

He thought the first step would be the hardest.

Ken saw the vintage tank in the museum.

Jennifer likes toast for breakfast.

It was a very tough examination last week.

We couldn't find a single trace of the missing dog.

Wendall laid a dangerous trap for the old fox.

He gently closed the heavy trunk of the car.

We loved to taste the expensive wine at the restaurant

The beautiful wool sweater was too costly.

\begin{tabular}{|c|c|}
\hline \multicolumn{2}{|c|}{ Primes } \\
\hline $\mathrm{S}$ & D \\
\hline arts & road \\
\hline angle & sport \\
\hline bill & inch \\
\hline bond & rock \\
\hline blood & staff \\
\hline change & method \\
\hline check & laugh \\
\hline court & board \\
\hline crowd & grace \\
\hline curve & dress \\
\hline down & work \\
\hline dead & fund \\
\hline decide & papers \\
\hline design & couple \\
\hline desk & jury \\
\hline expects & seconds \\
\hline firm & race \\
\hline fill & game \\
\hline floor & earth \\
\hline guide & flesh \\
\hline house & thing \\
\hline idle & rite \\
\hline lake & foam \\
\hline mass & bank \\
\hline nation & doctor \\
\hline parent & object \\
\hline plus & copy \\
\hline policy & mother \\
\hline price & study \\
\hline quick & fight \\
\hline roof & text \\
\hline simple & amount \\
\hline scene & hotel \\
\hline scope & pitch \\
\hline shake & press \\
\hline sharp & wagon \\
\hline sheet & birth \\
\hline ship & play \\
\hline show & edge \\
\hline skill & atoms \\
\hline status & guests \\
\hline stop & fall \\
\hline task & care \\
\hline taste & shore \\
\hline touch & cloud \\
\hline trade & labor \\
\hline trip & park \\
\hline truck & error \\
\hline wife & talk \\
\hline wood & baby \\
\hline
\end{tabular}

Note- $-\mathrm{H}$, homophone; $\mathrm{OC}$, orthographic control; $\mathrm{R}$, related; $\mathrm{U}$, unrelated; $\mathrm{S}$, similar; $\mathrm{D}$, different. 